\title{
ПЕРЕВОД ЖЕЛЕЗНОДОРОЖНОГО ТРАНСПОРТА НА ОТЕЧЕСТВЕННОЕ ПРОГРАММНОЕ ОБЕСПЕЧЕНИЕ
}

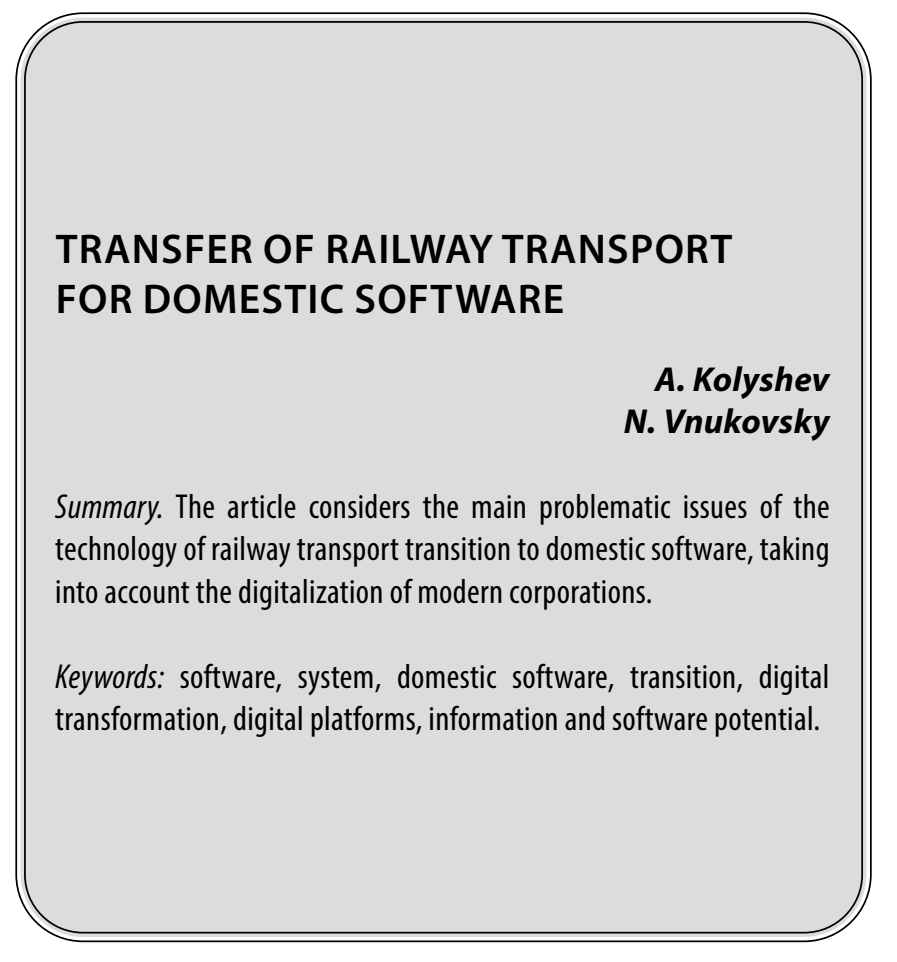

B настоящее время ни одна система не работает без программного обеспечения. Каждый день мы сталкиваемся с компьютерами, машинами, множеством технологий цифровизации, которые не могут существовать и давать результативность своей работы без системы программирования, такова участь современного мира.

Программное обеспечение (ПО, с англ.software) - некая совокупность программ, процедур, правил, которая обеспечивает функционирование программной системы или технологии, не требует доработок для получения качественной работы и достижения поставленных целей.

С помощью программного обеспечения происходит повышение производительности труда, эффективное увеличение качества предоставляемых товаров и услуг за счет автоматизации. Данный вопрос и рассматриваемый объект является очень актуальным на данный момент, в XXI веке, так как существуют определенные обстоятельства, в силу которых взламывают программное обеспечение и делают его общедоступным. Чтобы такого не происходило советуют использовать программное обеспечение отечественных производите-
Колышев Андрей Сергеевич

К.э.н., старший преподаватель, ФГБОУ ВО

«Уральский государственный университет путей сообщения», г. Екатеринбург

A.S.Kolyishev@bk.ru

Внуковский Николай Иванович

Д.э.н., профессор, ФГБОУВО «Уральский государственный университет путей сообщения»,

г. Екатеринбург

Vnukovsk@ya.ru

Аннотация. В работе рассмотрены основные проблемные вопросы технологии перехода железнодорожного транспорта на отечественное программное обеспечение с учетом цифровизации современных корпораций.

Ключевые слова: программное обеспечение, система, отечественный софт, переход, цифровая трансформация, цифровые платформы, информационно - программный потенциал.

лей. Взаимодействие ПО в цепочке мы можем рассмотреть на рисунке 1.

Из рисунка видно, что пользователи взаимодействуют с программными продуктами и операционной системой, а операционная система (ОС) взаимодействует с оборудованием и программой, тем самым защищая информацию.

Проблема, связанная с программным обеспечением очень актуальна и наглядна в рамках компании ОАО «Российские железные дороги». Известно, что к 2022 году планируется перевести все компании РЖД на отечественный софт. Такой переход является перспективной инициативой в условиях конкурентной борьбы на рынке индустрии по разработке программного обеспечения. Необходимо срочно закрепить законодательно-правовыми актами данное предложение, что положительно скажется на дальнейшем развитии российских программных продуктов и автоматизированных информационных систем [1].

Российские железные дороги проанализировали 112 платформ и систем программного обеспечения, созданных в России, вышли на новый уровень, сказав 


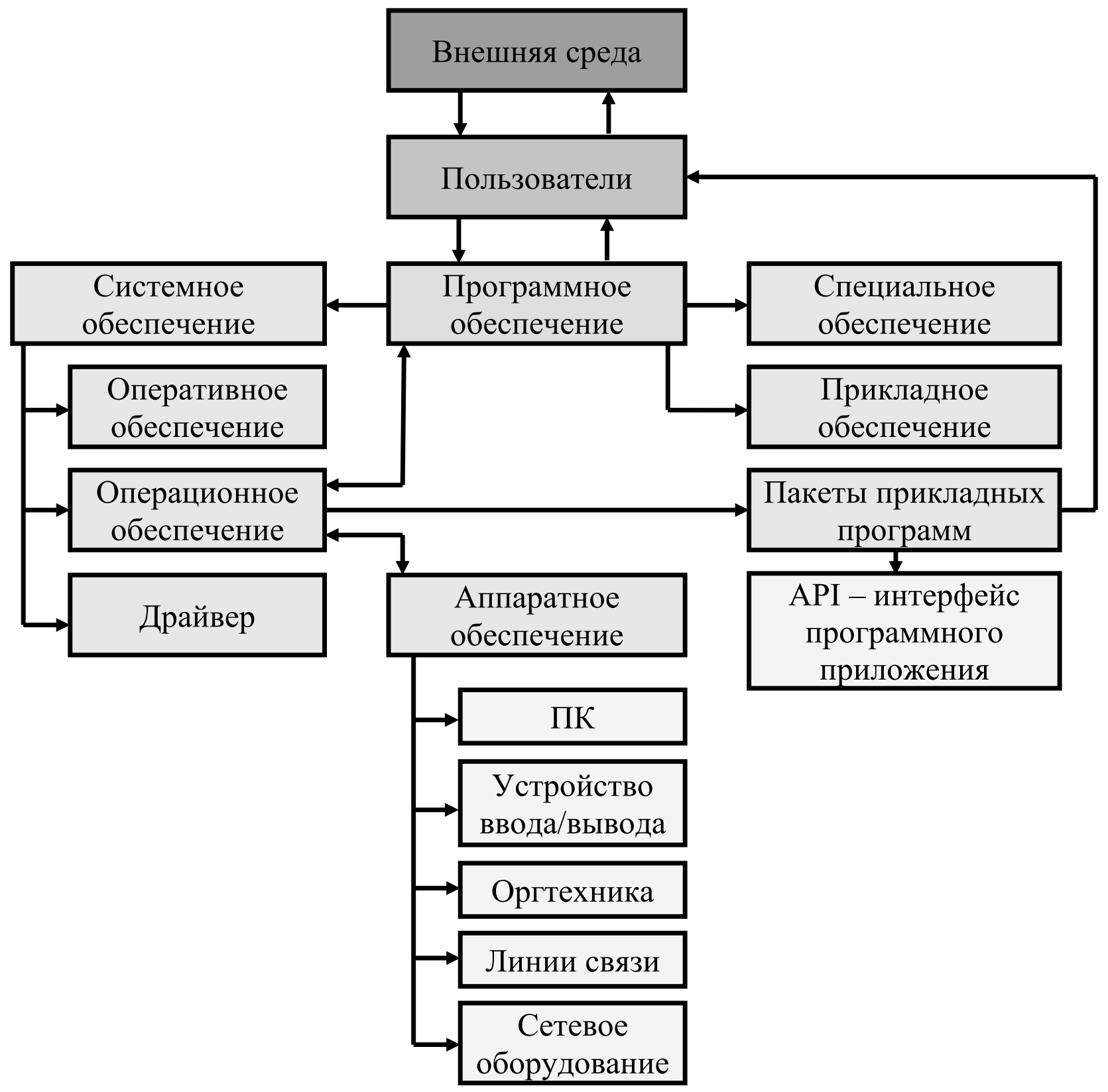

Рис. 1. Взаимодействие ПО с пользователями и оборудованием

о том, что доля отечественного ПО будет стремительно расти, и план мероприятий в этом направлении на 5 лет уже утвержден.

Также РЖД уже внедрили отечественную электронную почту, всевозможные браузеры, антиспам - для офисных работников.

Почему РжД решили перейти на отечественное программное обеспечение? Начнем с самого главного - с объема работы данной компании: в 2019 году РЖД транспортировала более 1 млрд. человек (если быть точнее - 1,2 млрд); перевезла 1,28 млрд. т. груза. В 2020 году данные показатели снизились на 42\%, изза сложившейся ситуации в мире: пассажирооборот составил 869 млн. человек, а грузооборот уменьшился на 3\% и составил 1,24 млрд. т. Подробнее информацию о пассажиро- и грузообороте мы можем рассмотреть на рисунках 2-3 [2].

Российские железные дороги перевозят более $25 \%$ всех пассажиров и более половины всех грузов, составляет 1,5\% ВВП России, поэтому причиной перехода на отечественное программное обеспечение стало 


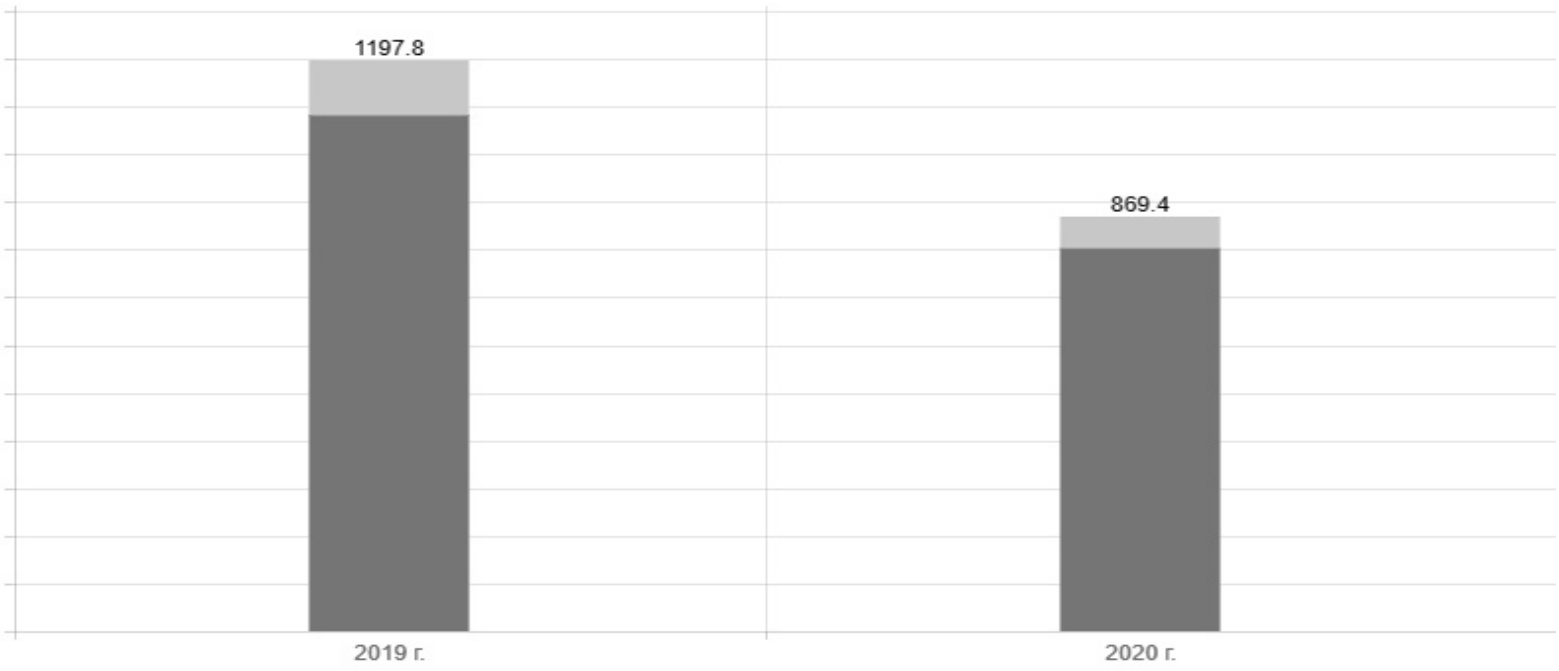

Рис. 2. Изменение пассажирооборота за год, млн. чел.

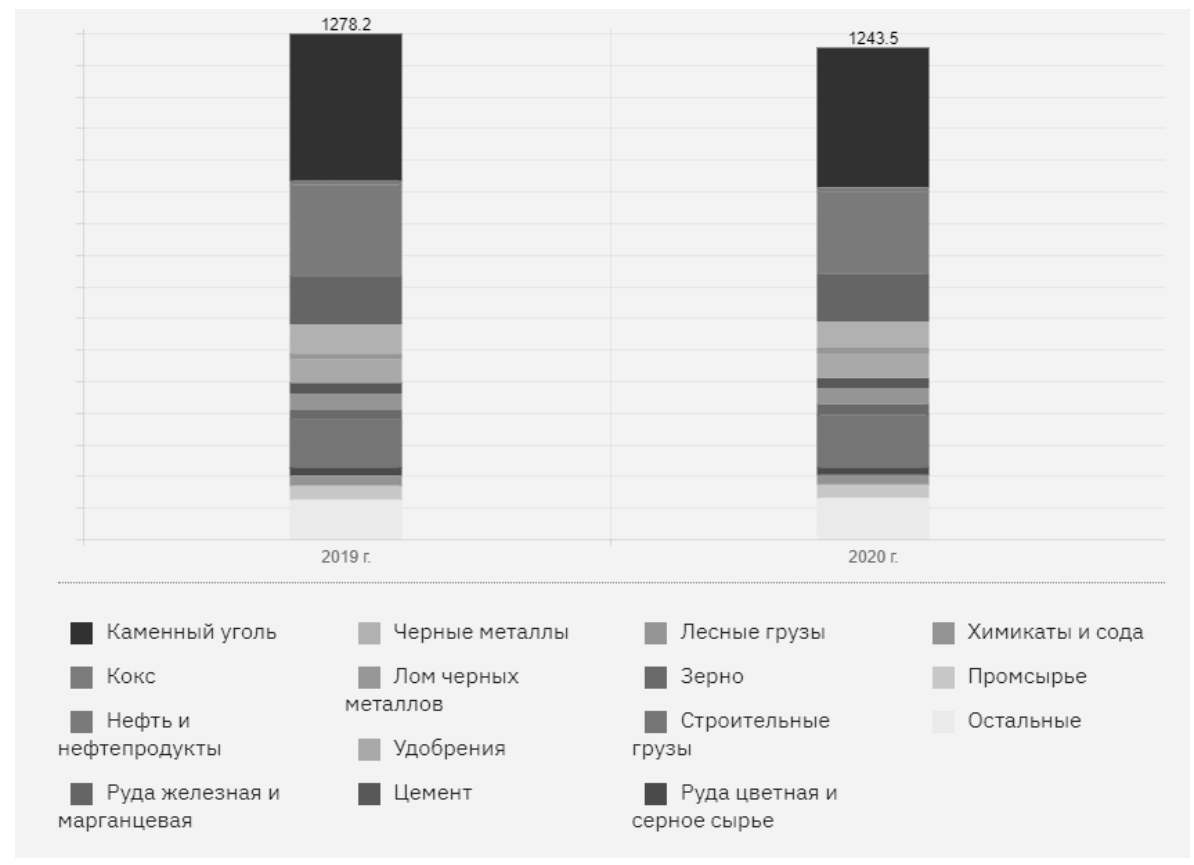

Рис. 3. Изменение грузооборота за год, млрд. тонн

число вовлеченных пользователей, а проблемой - ПО в иностранных руках.

Российские железные дороги готовы дать доступ к своей базе данных, готовы делиться всей информацией, связанной с работой компании, готовы идти на все ради качества, безопасности и надежности. Данная компания полностью готова к импортозамещению, что планируется сделать к 2022 году. В этом заключается основная роль в политике российских железных дорог с точки зрения безопасности в сфере информационных технологий, что напрямую взаимосвязано с кибербезо- пасностью, надежностью и качеством технологических процессов [3].

Второй причиной перехода на отечественный софт стало то, что разработчики IT-продуктов России должны помочь РЖД в реализации программы «Цифровая железная дорога».

Начнем с того, что РЖД - крупнейшая компания монополист, которая напрямую зависит от всех внешнеполитических и внешнеэкономических отношений России, поэтому предполагается, что данный проект 


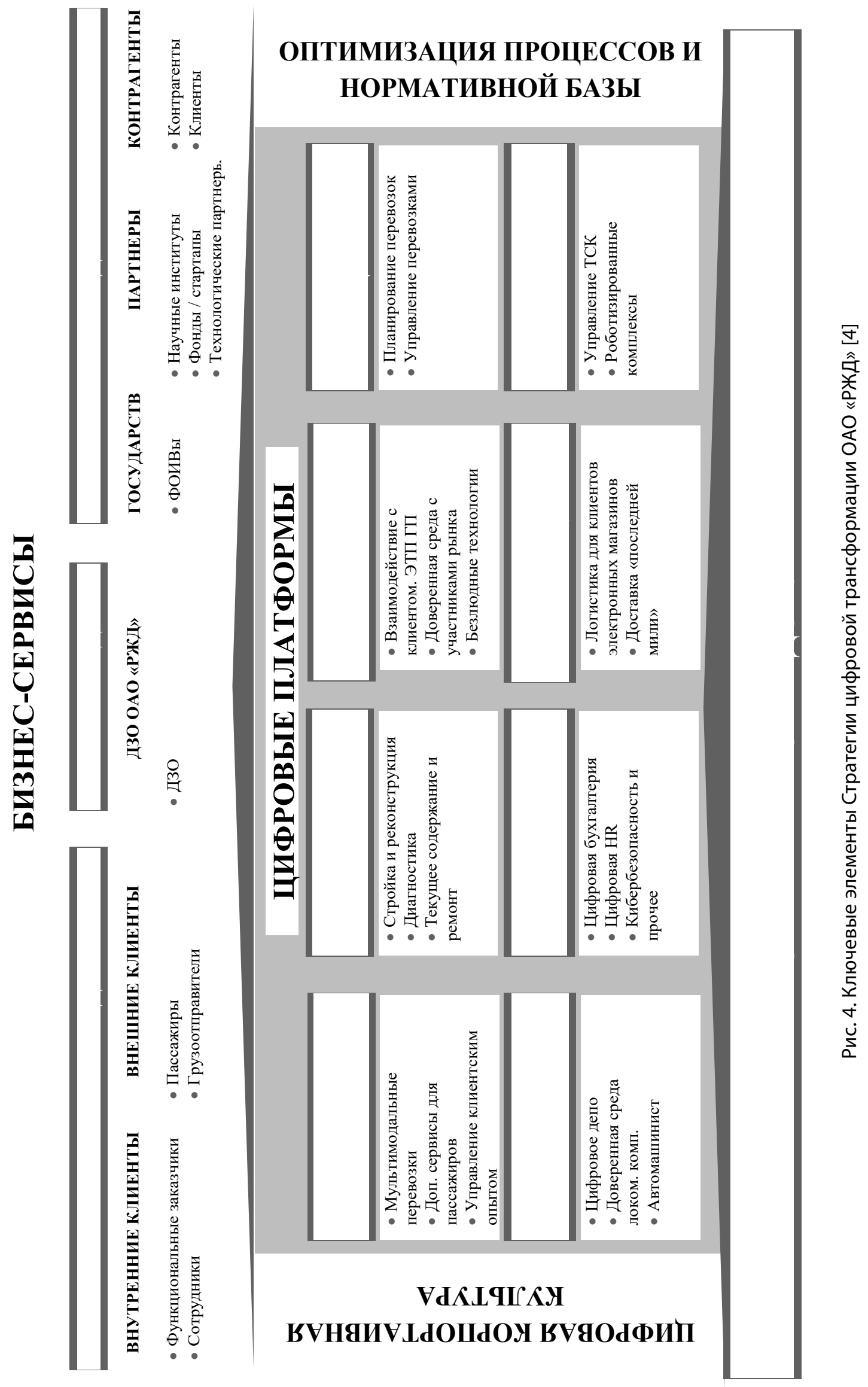


свяжет стратегию развития данной компании с программой «Цифровая экономика России». Стратегия РЖД включает:

- большие данные, то есть структурированные данные, которые обрабатываются программными инструментариями;

- промылиленный интернет, то есть межмашинные коммуникации;

- виртуальную и дополнительную реальности, то есть компьютерный мир и различного рода дополнения в виде приложений.

Реализация данной программы приведет к развитию информационных систем компании и к повышению качества при снижении стоимости владения. Это будет происходить из-за укрупнения и сокращения информационных систем, их унификации и единообразия в соответствии со стратегией цифровой трансформации ОАО «РЖД» (рисунок 4).

Переход к чему-то новому и современному всегда является особенностью развития. ОАО «РЖД» не должно стоять на месте, так как по данной компании можно определить каким является положение страны в предоставлении пассажирских и грузовых услуг, и постоянные изменения в развитии компаний является лишь положительным фактором. Также качество и безопасность являются не менее важными факторами данной компании, не должно быть никакой утечки информации, никто не должен вмешиваться в деятельность компании и взламывать данные для своих целей. Безопасность информации - одно из главных требований, которые предъявляются программным обеспечениям и информационным системам. Одно дело, когда контроль над компанией ведет свое государство, другое - иностранные компании и корпорации, поскольку это будет препятствовать иностранным интересам [4]. На сегодня многие стандартные базовые проекты и технологические процессы уже осуществляются при помощи собственных разработок и являются отечественными продуктами.

Таким образом, отечественное программное обеспечение позволит снизить уязвимость и зависимость от зарубежного воздействия, от утечки информации российских разработок, от риска киберугроз по защите корпоративных данных отечественных компаний и корпораций, уменьшит зависимость от программного импорта и реально приведет к реализации задач импортозамещения в области программного обеспечения и цифровых технологий $[5,6]$.

В российских компаниях и корпорациях есть определенный информационно-программный потенциал для разработки собственного программного обеспечения, создания больших структурированных данных, искусственного интеллекта, интернета вещей и других современных цифровых технологий, используя только отечественные реестры и программные разработки.

Анализируя достаточно высокий информационно-программный потенциал российских разработчиков и создателей программного обеспечения, а также возможности и тенденции развития цифровой трансформации в различных сферах цифровизации в деятельности ОАО «РЖД», что создает конкретную взаимосвязь бизнес-процессов цифровых платформ РЖД с реальной экономикой $[5,6]$.

\section{ЛИТЕРАТУРА}

1. Программное обеспечение России [Электронный ресурс]. Режим доступа: URL: https://habr.com/ru/post/433496/

2. Данные ОАО «РЖД» [Электронный ресурс]. Режим доступа: URL: https://company.rzd.ru/ru/9377\#cargo

3. Интервью Евгения Чаркина — специалиста РЖД по IT-технологиям [Электронный ресурс]. Режим доступа: URL: https://m.lenta.ru/tags/persons/ charkin-evgeniy/

4. Семион К.В. Стратегия цифровой трансформации [текст] / К.В. Семион // Автоматика, связь, информатика. — 2019.— № 4. - C. 5-6.

5. Внуковский Н.И. Тенденции трансформации корпораций с целью повышения их конкурентоспособности //Современная наука: актуальные проблемы теории и практики, Серия «Экономика и право» № 12/2.— 2017.—С.4-8.

6. Внуковский Н.И. Негативные особенности и прогнозные последствия цифровой экономики на развитие социального общества // Современная наука: актуальные проблемы теории и практики, Серия «Экономика и право» № 4. - 2021. - C. 11-14.

( ) Колышев Андрей Сергеевич ( A.S.Kolyishev@bk.ru ), Внуковский Николай Иванович (Vnukovsk@ya.ru ).

Журнал «Современная наука: актуальные проблемы теории и практики» 